\title{
Pyrolysis of wood at high temperature: The influence of experimental parameters on gaseous products
}

\author{
J.-M. Commandré ${ }^{\mathrm{a}, *}$, H. Lahmidi ${ }^{\mathrm{b}}$, S. Salvador ${ }^{\mathrm{b}}$, N. Dupassieux ${ }^{\mathrm{c}}$ \\ a UPR 42 Biomasse Energie, CIRAD, 73 rue JF Breton, TA B42/16, 34398 Montpellier Cedex 5, France \\ ${ }^{\mathrm{b}}$ Centre RAPSODEE, UMR 2392 CNRS, Ecole des Mines d'Albi-Carmaux, route de Teillet, 81013 Albi CT Cedex 09, France \\ c Institut Français du Pétrole, BP 369390 Vernaison, France
}

\begin{abstract}
A B S T R A C T
The pyrolysis of wood was carried out in an Entrained Flow Reactor at high temperature $\left(650\right.$ to $\left.950{ }^{\circ} \mathrm{C}\right)$ and under rapid heating conditions $\left(>10^{3} \mathrm{Ks}^{-1}\right)$. The influence of the diameter and initial moisture of the particle, reactor temperature, residence time and the nature of the gaseous atmosphere on the composition of the gaseous products has been characterised. Particle size, between 80-125 and 160-200 $\mu \mathrm{m}$, did not show any impact. Pyrolysis and tar cracking essentially happen in very short time period: less than $0.6 \mathrm{~s}$; the products yields are only slightly modified after $0.6 \mathrm{~s}$ in the short residence times (several seconds) of our experiments. Higher temperatures improve hydrogen yield in the gaseous product while $\mathrm{CO}$ yield decreases. Under nitrogen atmosphere, after $2 \mathrm{~s}$ at $950{ }^{\circ} \mathrm{C}, 76 \%$ (daf) of the mass of wood is recovered as gases: $\mathrm{CO}, \mathrm{CO}_{2}$, $\mathrm{H}_{2}, \mathrm{CH}_{4}, \mathrm{C}_{2} \mathrm{H}_{2}, \mathrm{C}_{2} \mathrm{H}_{4}$ and $\mathrm{H}_{2} \mathrm{O}$. Tests performed under steam partial pressure showed that hydrogen production is slightly enhanced.
\end{abstract}

Keywords:

Biomass

Gasification

Rapid pyrolysis

Entrained flow reactor

Wood

\section{Introduction}

The necessity for alternative energy sources has caused renewed interest in the use of biomass, since this renewable fuel does not contribute to increased $\mathrm{CO}_{2}$ concentration in the atmosphere $[1,2]$. Because of tension on petroleum cost, second generation biofuels produced by Fischer-Tropsch synthesis after biomass gasification show an increasing interest. The physical and chemical mechanisms involved in biomass steam gasification are still poorly understood [3], especially under high temperatures $(1073 \mathrm{~K}<\mathrm{T}<1273 \mathrm{~K})$ and high heating rate $\left(>10^{3} \mathrm{Ks}^{-1}\right)$. Our work focuses on processes occurring at the particle scale during the first seconds of the transformation. This first stage-named "pyrolysis" in our study-gathers both biomass decomposition, often called "primary pyrolysis" or "devolatilisation", and the secondary cracking reactions of the vapours produced during primary pyrolysis.

In literature, investigations on pyrolysis characterization have been mainly carried on slow pyrolysis [4]; high heating rate pyrolysis of biomass has not been studied as closely, particularly in the high temperature domain [5,6]. Published high temperature pyrolysis experiments on biomass involve reactors such as fluid bed reactors [7,8], radiant heating techniques [9], drop tube furnaces and entrained flow reactors [10-12]. In the present paper, experiments are performed in a free fall reactor, also called entrained flow reactor (EFR).

\footnotetext{
* Corresponding author. Tel.: + 334676159 05; fax: + 33467616515 . E-mail address: jean-michel.commandr@cirad.fr (J.-M. Commandré).
}

This reactor is an interesting analytical tool to study the global reaction of flash pyrolysis [3,10,13-19], since very high heating rates of the particles can be obtained. Moreover, the residence time can be varied over a range of a few seconds, and the particles can be assumed to be isolated from each other, which makes interpretation easier $[14,17]$. Up to now, few experiments have been performed under the operating conditions of interest, the most complete set of data being given by Zanzi $[18,19]$. Zanzi et al. have studied the effect of the process conditions, such as temperature and particle size, on the product of high heating rate pyrolysis of agricultural residues, including gas composition and char reactivity, in a free fall reactor. They showed that higher reaction temperature ( 800 to $1000{ }^{\circ} \mathrm{C}$ ) led to lower yields of tars and higher yields of gaseous products. In addition, pyrolysis of smaller particles ( 0.5 to $1 \mathrm{~mm}$ ) improved the char reactivity for combustion or gasification [20]. Results found by Guerrero et al. [1] showed that the reactivity to oxygen of the char produced by eucalyptus pyrolysis increases with the heating rate of biomass particles.

Several works $[1,11,13,25]$ have focused on gaseous products. They showed that gaseous amounts increase with temperature, residence time, and heating rate. Li et al. [13] showed that solid and liquid yields increase with particle diameters, whereas gaseous amounts decrease. The main gaseous products during flash pyrolysis of biomass are carbon monoxide $(\mathrm{CO})$, hydrogen $\left(\mathrm{H}_{2}\right)$, carbon dioxide $\left(\mathrm{CO}_{2}\right)$, methane $\left(\mathrm{CH}_{4}\right)$ and other light hydrocarbons. Studies interested in these gaseous products [21] have shown that the ratio $\mathrm{CO} / \mathrm{CO}_{2}$ increases with temperature, but decreases when the heating rate increases. For a temperature range of $500-800{ }^{\circ} \mathrm{C}$, Li et al. confirmed 
that $\mathrm{H}_{2}$ and $\mathrm{CO}$ concentrations increase with temperature, and the $\mathrm{H}_{2} / \mathrm{CO}$ ratio increases with particle diameters. Moreover, Couhert et al. [22] showed that gaseous products of high heating rate pyrolysis of wood particles are slightly influenced by wood nature, and are similar for soft and hard wood.

The parameters which can influence biomass gasification, and particularly pyrolysis as the first reaction step, are particle diameter particle initial moisture, reactor temperature and residence time, and the nature of the gaseous atmosphere. In our study, flash pyrolysis of wood particles was characterised over a range for each parameter:

- temperature: 650 to $950{ }^{\circ} \mathrm{C}$;

- residence time: 0.5 to $2 \mathrm{~s}$;

- size of wood particles: 80-125 $\mu \mathrm{m}$ and 160-200 $\mu \mathrm{m}$;

- particle initial moisture: dried wood and $10.7 \%$ (natural moisture)

- nature of the atmosphere: $\mathrm{N}_{2}$ and $\mathrm{N}_{2}$ containing $10 \% \mathrm{H}_{2} \mathrm{O}$

The purpose of our study was to evaluate the influences of each one of these parameters on the nature of gaseous products and on their amounts during high temperature flash pyrolysis of wood. This reaction is the first step in the conversion of biomass to syngas $\left(\mathrm{H}_{2}\right.$ and $\mathrm{CO}$ ) in a fluidised bed and/or entrained flow reactors under development at this time.

\section{Experiments}

The experiments were carried out with pine wood. Table 1 gives the results of the proximate and the ultimate analysis, as well as the natural moisture content of pine wood. Levels of ash and volatile matters are measured following the standard methods. Results are in agreement with those found by ECN in their Phyllis Database [23]: this wood contains $10.7 \%$ of natural moisture, low ash content and very low $\mathrm{N}$ and $\mathrm{S}$ content.

Experiments were carried out at laboratory scale in an Entrained Flow Reactor (EFR) under high temperatures ( 650 to $950{ }^{\circ} \mathrm{C}$ ) and high heating rate $\left(>10^{3} \mathrm{Ks}^{-1}\right)$. This EFR is schematically described in Fig. 1 . The complete description of the apparatus and its thermal and hydrodynamic characterization were given in previous works from Van de Steene [24] and Commandré [17]. A steam generator and a steam over-heater were added to conduct experiments under different steam partial pressure.

It is a $75 \mathrm{~mm}$ i.d. and $2 \mathrm{~m}$ long tube into which an isothermal reaction zone is fed with an electrically preheated laminar gas flow. Besides the nitrogen, a controlled steam flow could be added thanks to a water mass flow meter/controller and a steam generator that produced steam at $150{ }^{\circ} \mathrm{C}$.

The powdered solid is injected through a hot-oil cooled feeding probe avoiding steam condensation, and dispersed over the cross-section of

Table 1

Proximate, ultimate, and moisture analysis of pine wood.

\begin{tabular}{lcc}
\hline Proximate analysis & wd\% & Pine wood \\
\hline Ash & & 0.4 \\
Volatile matter & & 82.3 \\
Fixed carbon (by difference) & 17.3 \\
& & \\
Ultimate analysis & waf\% & \\
\hline C & & 45.46 \\
H & & 5.89 \\
O (by difference) & & 48.65 \\
N & & $<0.1$ \\
S & w\% & 10.7 \\
& & \\
Moisture & & \\
\hline
\end{tabular}

w\%: mass percent.

wd\%: mass percent dry.

waf\%: mass percent ash free. the reactor using a dispersion dome. It is pyrolysed for a controlled residence time before being sampled by a hot-oil cooled probe.

The solid injection consists of a low velocity conveyor belt that ensures an accurate solid mass flow rate. The belt is fed from a $\mathrm{V}$-shaped rail along which a precisely weighted quantity of solid is regularly spread using a calibrated wedge. The mass flow of the biomass was $1 \mathrm{~g} / \mathrm{min}$, which ensures that particles may be assumed to be isolated from each other. In these conditions of gas and solid flow, the particles density is low in order to keep isothermal the flow even exo or endothermal reactions are involved. Temperature measurements with thermocouples on radial and axial position along the reactor have shown that the reactor is isothermal after $0.30 \mathrm{~m}$ away from the solid injection $[17,25]$.

The gas and solid phases can be collected at different heights ( $\mathrm{z}$ ) using a hot-oil cooled sampling probe, allowing precise control of the residence time. Residence time of gas was calculated for the sampled section around the axis of the reactor by considering the average gas velocity in the section. Residence time for particles was calculated for each sample taking into account the slip velocity of the solid in the gas.

Downstream the sampling probe, a condenser was used to remove water from gases prior to analysis. The water remaining in gases after the condenser was quantified using a cooled-mirror hygrometer. The sum of the mass of condensed water and of the mass of water quantified by the hygrometer in gases represents the water contained in the sampled gases.

After separating gas from particles and water, the gases are forwarded to the analysers, via a heated line:

- a Fourier Transform InfraRed (FTIR) analyser to quantify continuously $\mathrm{CO}, \mathrm{CO}_{2}, \mathrm{CH}_{4}, \mathrm{C}_{2} \mathrm{H}_{2}, \mathrm{C}_{2} \mathrm{H}_{4}, \mathrm{C}_{2} \mathrm{H}_{6}, \mathrm{C}_{3} \mathrm{H}_{8}, \mathrm{NO}, \mathrm{NO}_{2}, \mathrm{~N}_{2} \mathrm{O}, \mathrm{NH}_{3}$, $\mathrm{HCN}$ and $\mathrm{SO}_{2}$;

- a Non Dispersive InfraRed (NDIR) analyser for $\mathrm{CO}, \mathrm{CO}_{2}, \mathrm{SO}_{2}$, NO and $\mathrm{NO}_{\mathrm{X}}$ concentrations coupled with a paramagnetic analyser for $\mathrm{O}_{2}$ concentration;

- a Thermal Conductivity Detector (TCD) for $\mathrm{H}_{2}$ concentration;

- a Methane and Total hydrocarbons analyser, using 2 Flame Ionisation Detectors (FID).

The experimental conditions for all experiments are summarized in Table 2. As illustrated in Fig. 2, the repeatability-checked for experiments at the two positions $50 \mathrm{~cm}$ and $90 \mathrm{~cm}$ and at $900{ }^{\circ} \mathrm{C}$-was satisfactory (variation $<6 \%$ ).

Two size fractions ( $80-125 \mu \mathrm{m}$ and $160-200 \mu \mathrm{m}$ ) were selected by pneumatic sieving to remove the fine particles under $80 \mu \mathrm{m}$, then by manual sieving to prepare the two size fractions.

In the following figures where gas species are plotted, the gas yields are expressed through the ratio of the mass of gas on the initial wood mass (wet, unless specified) injected.

Since the amount of ash is very low in wood, the normalised ashtracer method usually used to measure solid conversion could not be applied for this test.

\section{Results and discussion}

\subsection{Observations of wood particles}

A view of the initial pine wood particles under scanning electron microscope is presented in Fig. 3-a. One can observe different shapes of particles with various lengths; the majority is stick-shaped. Their dimensions are very different and the ratio between the length and the width of a particle varies from 2 to 10 .

After pyrolysis at $900{ }^{\circ} \mathrm{C}$ for $2 \mathrm{~s}$ under $\mathrm{N}_{2}$, two categories of particles can be noticed (Fig. 3-b). The first ones have preserved their initial form while contracting. The second ones have undergone a drastic modification in morphology: they have become hollow spheres. The diameter of the final char particles approximately 


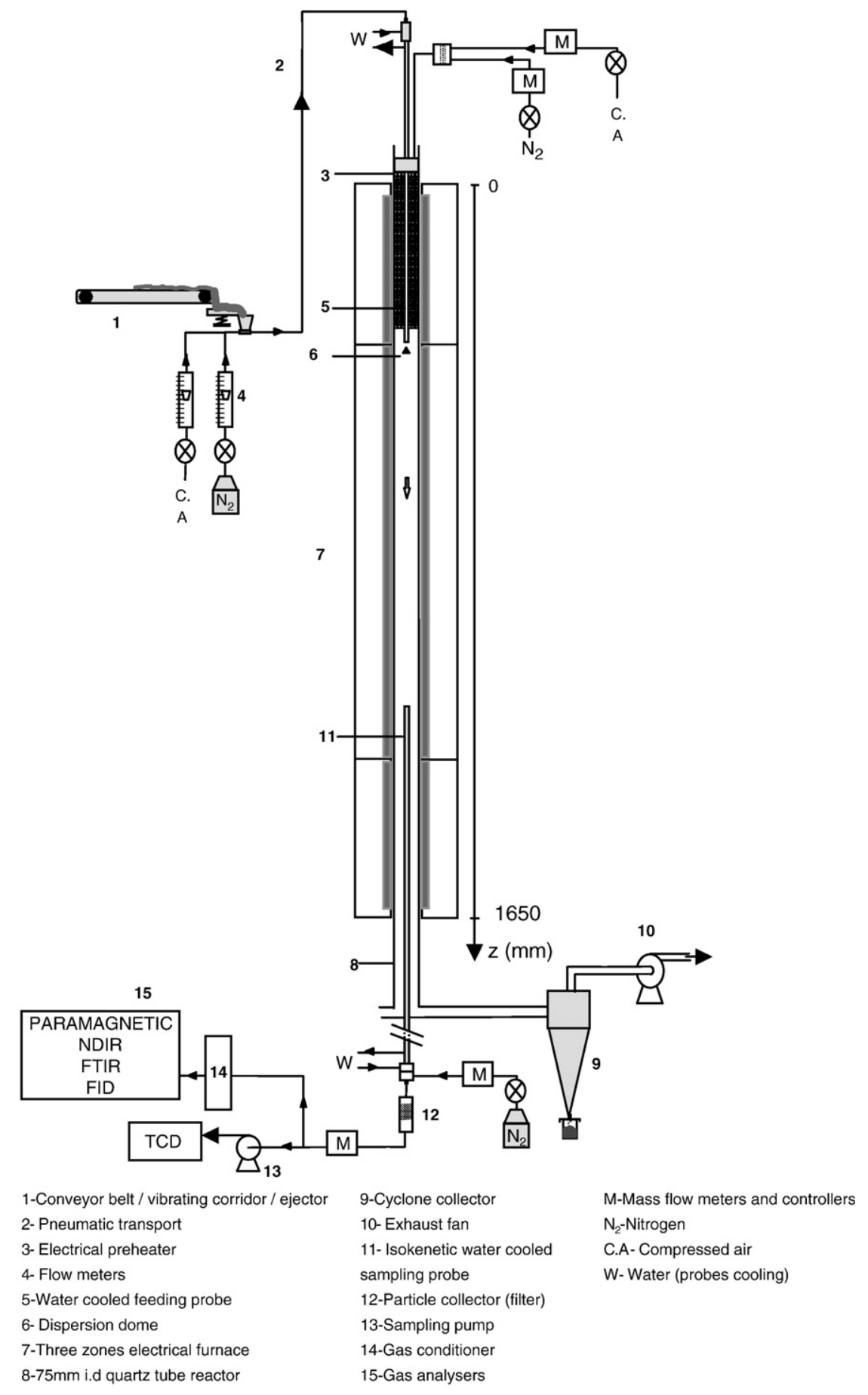

Fig. 1. Schematic view of the Entrained Flow Reactor.

corresponds to the width of the initial wood particles. These phenomena may be an effect of temperature [26]. These observations let us think that a fusion phenomenon occurred and that the particles pass through a plastic phase with gas generation inside. Considering that biomass is a polymer, such behaviour of wood during pyrolysis seems logical and is in agreement with the "fusion-like phenomenon" of wood stated by Lédé et al. [27] and the existence of an intermediate liquid compound (ILC).

\subsection{Mass balance}

From the results of experiments, it is possible to propose a mass balance in terms of yields of solid residue, gas and tars. Such results are particularly relevant for considerations of eventual steam reforming of the pyrolysis products to supply a syngas ( $\mathrm{CO}$ and $\mathrm{H}_{2}$ ). In some processes, the solid residue might also be separated from the gases and tars, to be burned separately and supply the energy required by the process. The experiment was carried out at $900{ }^{\circ} \mathrm{C}$ for around $2 \mathrm{~s}$ under nitrogen. For this specific experiment, a high gassampling flow rate was used to collect all the products (gas, tars and solid residues) in the reactor.

Char and tar mass quantification was carried out using the following procedure. During the experiment, the major part of the char residue was recovered in a settling box and in a filter at the outlet of the sampling probe and weighed once the experiment was over. Then, the sampling probe was cleaned using acetone. The liquid 
Table 2

The characteristics of experiments carried out under nitrogen and under steam.

\begin{tabular}{|c|c|c|c|c|c|c|}
\hline Influence of & Particle size $\mu \mathrm{m}$ & Flow of nitrogen $\mathrm{l} / \mathrm{min}$ at STP & Flow of steam $1 / \mathrm{min}$ at STP & Ratio Steam $/ \mathrm{N}_{2}$ vol.\% & Temperature ${ }^{\circ} \mathrm{C}$ & Residence time s \\
\hline Residence time & $160-200$ & 18 & 0 & 0 & 900 & 0.5 to 1.5 \\
\hline Temperature & $160-200$ & 23 & 0 & 0 & 650 to 950 & 1.4 to 1.6 \\
\hline \multirow[t]{2}{*}{ Particle size } & $80-125$ & 18 & 0 & 0 & 900 & 1.9 \\
\hline & $160-200$ & 18 & 0 & 0 & 900 & 1.9 \\
\hline Natural wood moisture & $160-200$ & 23 & 0 & 0 & 850 & $0.9 ; 1.3 ; 1.45$ \\
\hline \multirow[t]{2}{*}{ Steam concentration } & $160-200$ & 18 & 0 & 0 & 900 & 1.9 \\
\hline & $160-200$ & 14.2 & 3.8 & 10 & 900 & 1.9 \\
\hline
\end{tabular}

obtained contained tars, as well as chars that had been stuck on the probe by these tars. This liquid was filtered and solids were washed with acetone in order to separate the solid residue from the liquid phase; the mass of chars weighed was added to the previous one.

The remaining liquid was left under a hood for $48 \mathrm{~h}$. The viscous residue after liquid evaporation was considered to be the mass of tars. The mass difference-after and before experiment-of the filter located downstream of the sampling probe and settling box was also quantified as tars.

The experiment was repeated three times; the results obtained are presented in Fig. 4, as a \% of the mass of the initial biomass. The term "gas" represents the sum of the yields of the gases that were analysed, i.e. $\mathrm{H}_{2}, \mathrm{CO}, \mathrm{CO}_{2}, \mathrm{CH}_{4}, \mathrm{C}_{2} \mathrm{H}_{4}, \mathrm{C}_{2} \mathrm{H}_{2}$ and $\mathrm{H}_{2} \mathrm{O}$. The quantification of gases
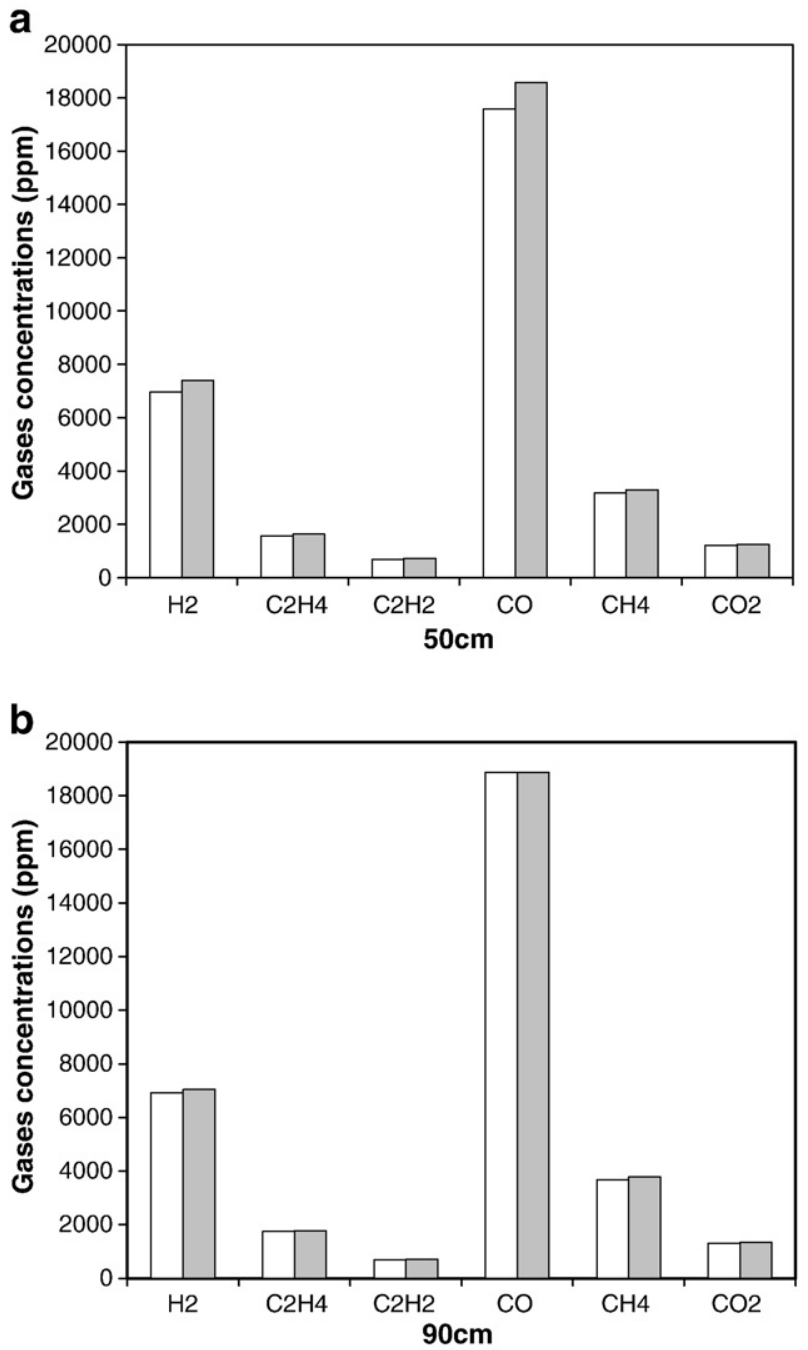

Fig. 2. Repeatability of pyrolysis experiments of wood at $900{ }^{\circ} \mathrm{C}$ at 50 (a) and $90 \mathrm{~cm}$ (b) from the injection point. appears to be very repeatable, and the mass released by particles is as high as $76 \%$. The accuracy of char quantification is not as good: the char yields vary between $4.4 \%$ and $7.7 \%$. This can be attributed to the difficulty in cleaning and collecting all particles stuck with tars in the sampling probe.

The quantification of tars is repeatable (1.4 to 1.5\%). The measured mass of tars is in accordance with the value of $1 \%$ found by Zanzi [18]. Nevertheless, doubts remains about the quantity of hydrocarbon species that are evaporated with acetone during the protocol.

Fig. 4 also shows that approximately $16 \%$ w of the wood initial mass injected in the reactor is non-quantified. It is difficult at this stage to attribute this mass to non-quantified gases, char or tar. In order to specify the nature of the missing $16 \% \mathrm{w}$, we carried out mass balances for the elements $\mathrm{C}, \mathrm{H}$ and $\mathrm{O}$. A balance for each element-detailed in Fig. $5-$ indicates that $10 \% \mathrm{w}$ of carbon, $1 \% \mathrm{w}$ of hydrogen and $6 \% \mathrm{w}$ of

a

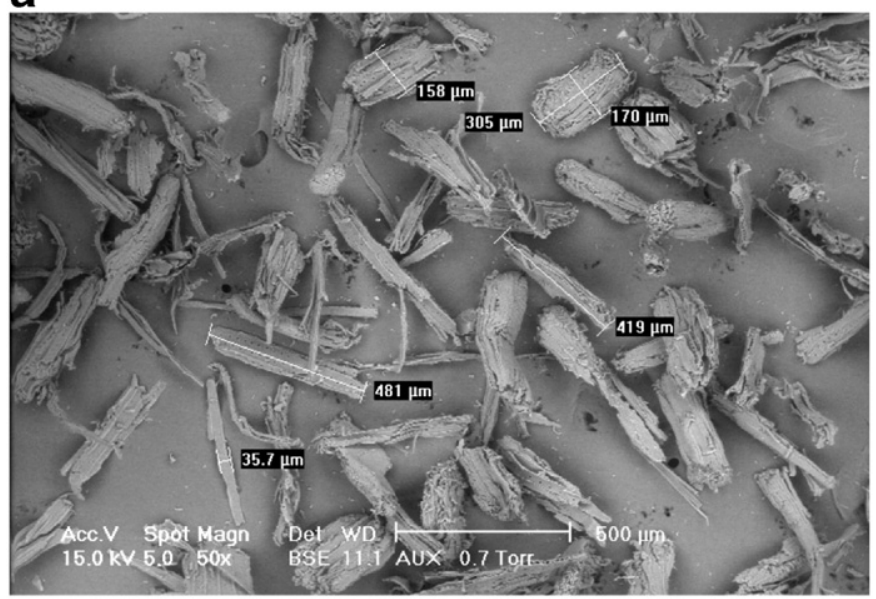

b

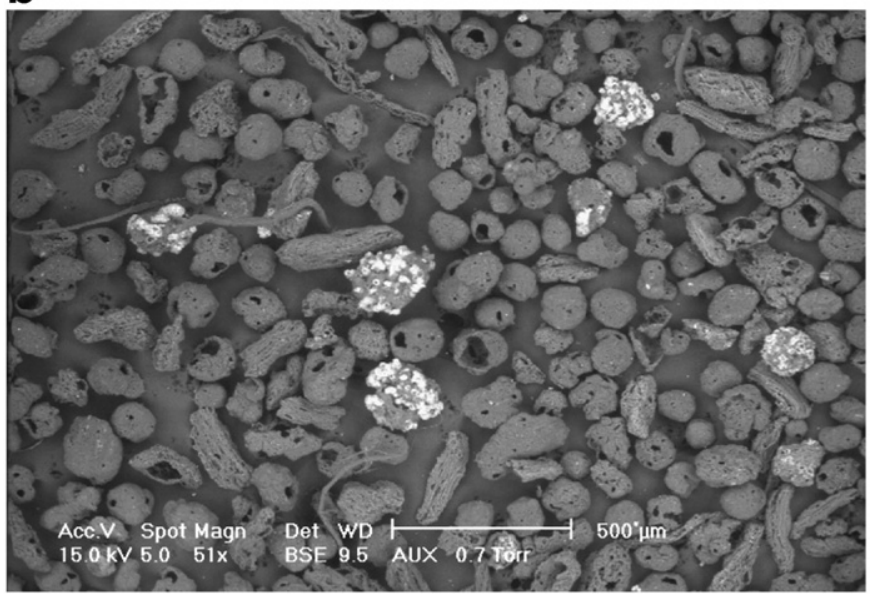

Fig. 3. Observation of initial and pyrolysed wood under electron microscope. (a) Initial wood; (b) pyrolysed wood under $\mathrm{N}_{2}$; scale is $500 \mu \mathrm{m}$. 


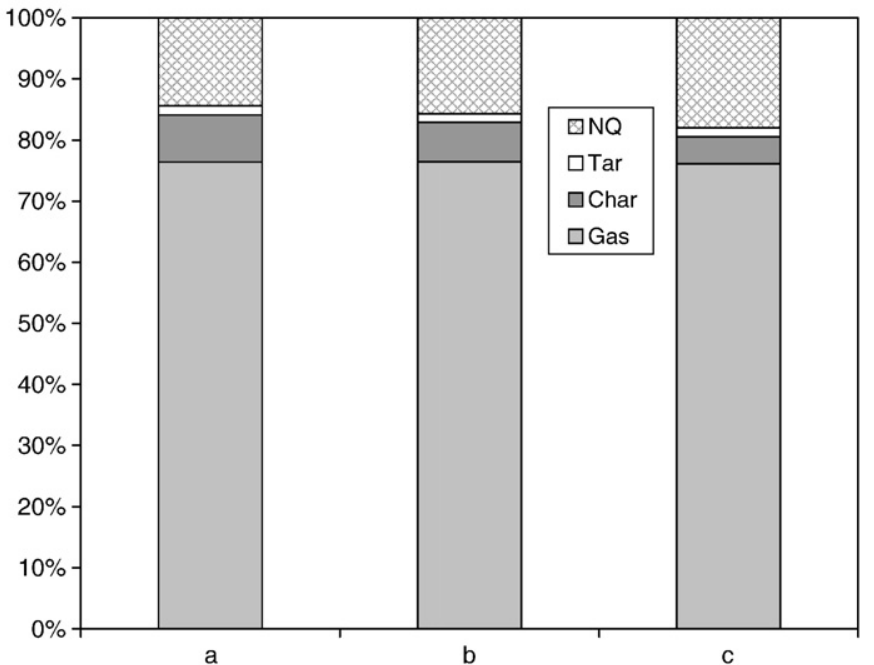

Fig. 4. Mass balance (three experiments a, b, c) realised after wood pyrolysis at $900{ }^{\circ} \mathrm{C}$ under $\mathrm{N}_{2} ; \mathrm{H}_{2} \mathrm{O}$ is quantified with gas; NQ stands for Non Quantified mass.

oxygen are missing. The average formula of the equivalent missing product is $\mathrm{C}_{10} \mathrm{H}_{12} \mathrm{O}_{4}$, close to the formula for coniferyl alcohol $\left(\mathrm{C}_{10} \mathrm{H}_{12} \mathrm{O}_{3}\right)$ indicated by ECN [28].

\subsection{Influence of particle size}

As far as particle diameter is concerned, experiments were carried out at $900{ }^{\circ} \mathrm{C}$ with two classes of particle size of pine: [80-125] and [160-200] $\mu \mathrm{m}$. At this temperature, comparing the different gas species in the product gas at the reactor outlet, very similar results are obtained for both sizes (Fig. 6). Since the pyrolysis process is very fast, no conclusion can be drawn immediately in terms of the apparent reaction kinetics. One could expect the particles with different diameters to have undergone different heating rates. Nevertheless, as demonstrated previously [24], the heating rate in such conditions is controlled essentially by the mixing of the flows of the cold transport gas and the hot atmosphere gas. It is likely that it was similar for both particle sizes, which could explain the similarity in the gases produced. In these conditions, this result shows that for both particle sizes there is no heat and mass transfer limitation for the solid-gas reaction, which is in accordance to [3].

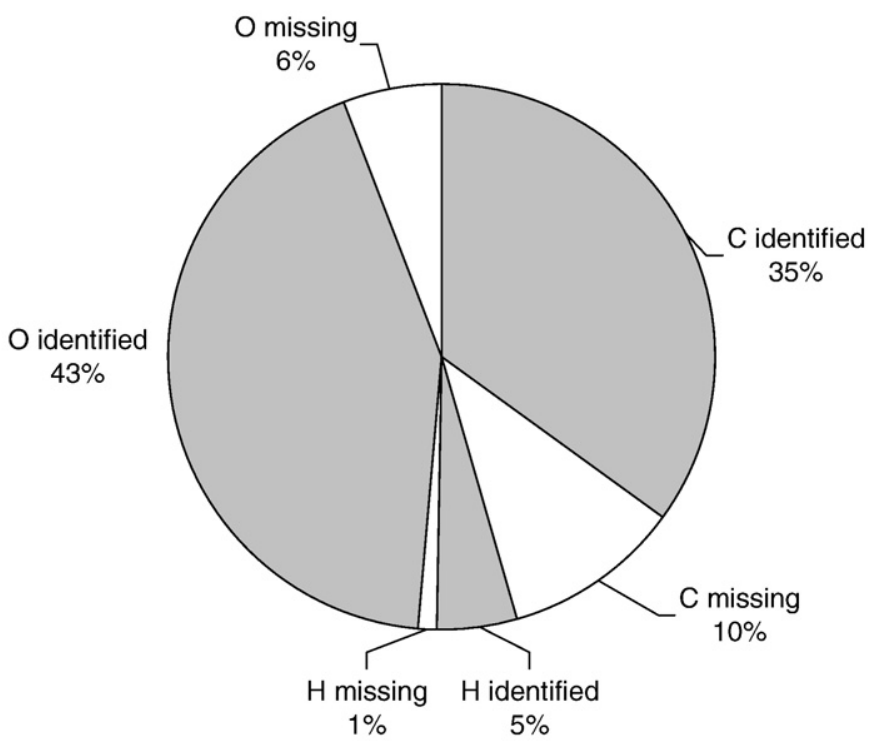

Fig. 5. Mass balance by element: $\mathrm{C}, \mathrm{H}, \mathrm{O}$ in \% of the mass of initial biomass.

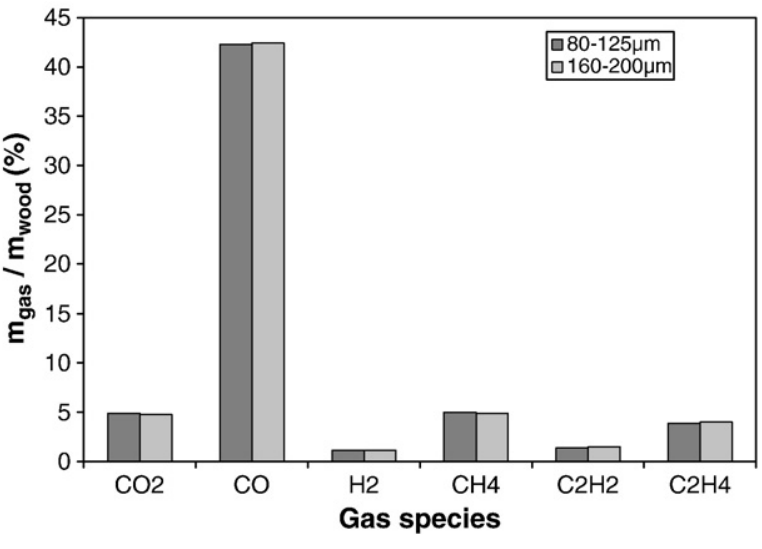

Fig. 6. Gas species mass normalised to the initial mass of wood released after $2 \mathrm{~s}$ pyrolysis of two sizes of wood particles at $900{ }^{\circ} \mathrm{C}$ under $\mathrm{N}_{2}$.

We should reiterate here that the observed gases are the result of primary pyrolysis and also of tar cracking. One might also imagine that the primary products of pyrolysis were different for the two particle sizes, but that tar cracking and gas phase reactions brought them to similar compositions.

\subsection{Influence of residence time}

Pine wood particles were pyrolysed at $850{ }^{\circ} \mathrm{C}$ in the EFR. Results of gas yields during pyrolysis are plotted in Fig. 7. Except for hydrogen, the yields of all species globally appear to be virtually unchanged after the first measurement point at $0.6 \mathrm{~s}$. In the pyrolysis process, primary volatile matters are produced first. They consist mainly of some permanent gases and heavy hydrocarbons, which are then cracked to form additional permanent gases. Therefore, it is likely that both pyrolysis and tar cracking reactions only slowly evolve during the short residence time involved in our experiments.

This figure also shows that $\mathrm{CO}$ is the main gas released by wood pyrolysis. Hydrogen is important in the molar fraction, but it has the lowest yield in the mass fraction. The species $\mathrm{C}_{2} \mathrm{H}_{4}$ shows increasing yields with time while $\mathrm{C}_{2} \mathrm{H}_{2}$ and $\mathrm{H}_{2}$ decrease. Based on these observations, the homogeneous reactions of hydrogenation

$\mathrm{C}_{2} \mathrm{H}_{2}+\mathrm{H}_{2} \rightleftarrows \mathrm{C}_{2} \mathrm{H}_{4}$

can be assumed to occur inside the reactor. However, the mass balance of this reaction can only explain $25 \%$ of the decrease observed on $\mathrm{H}_{2}$ with residence time.

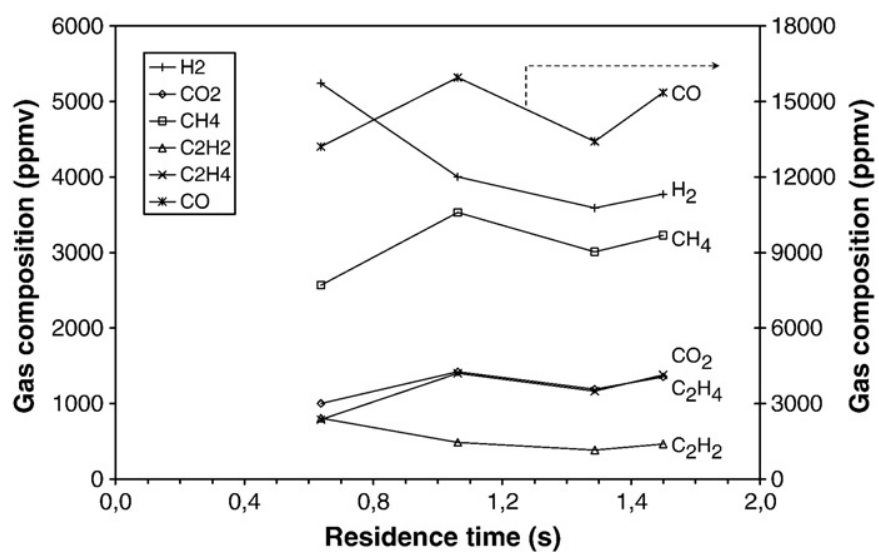

Fig. 7. Time evolution of the gas composition (ppmv) during pyrolysis of wood at $850^{\circ} \mathrm{C}$ under $\mathrm{N}_{2}$. 


\subsection{Influence of reactor temperature}

As discussed in the Introduction, increasing the temperature and/ or the heating rates supports the gas production while minimising the production of solid residue. However, the nature of gases also varies with the reaction temperature. In our experiments, pine wood was pyrolysed under nitrogen between 650 and $950{ }^{\circ} \mathrm{C}$ and sampled at $80 \mathrm{~cm}$ from the injection point, i.e. when the pyrolysis had terminated.

Fig. 8 shows the gas yields versus temperature. Note that in this figure the yield of $\mathrm{H}_{2}$ was multiplied by 10 and that of $\mathrm{CO}$ was divided by 10 . Hydrogen production is clearly improved by an increase in temperature: its yield is zero at $650{ }^{\circ} \mathrm{C}$, it appears at $700{ }^{\circ} \mathrm{C}$ and its mass percentage rises to over $1 \%$ at $950{ }^{\circ} \mathrm{C}$. These results lead us to think that higher pyrolysis temperature would lead to an even higher percentage of hydrogen.

The increase in hydrogen yield is accompanied by an increase in $\mathrm{C}_{2} \mathrm{H}_{2}$ from $0.3 \%$ w at $650{ }^{\circ} \mathrm{C}$ to more than $2 \% \mathrm{w}$ at $950{ }^{\circ} \mathrm{C}$. Contrary to $\mathrm{C}_{2} \mathrm{H}_{2}$, the mass percentage of $\mathrm{C}_{2} \mathrm{H}_{4}$ tends to decrease at temperatures above $850{ }^{\circ} \mathrm{C}$ according to results found by Dupont et al. [29]. The reaction of $\mathrm{C}_{2} \mathrm{H}_{4}$ consumption to produce $\mathrm{C}_{2} \mathrm{H}_{2}$ and $\mathrm{H}_{2}$ is thermodynamically favoured when temperature increases. This could explain why $\mathrm{C}_{2} \mathrm{H}_{4}$ amounts decrease when temperature increases in favour of $\mathrm{C}_{2} \mathrm{H}_{2}$.

The concentrations of $\mathrm{CO}_{2}$ increase slightly until $900{ }^{\circ} \mathrm{C}$, and seem to stabilise above this temperature. The quantity of $\mathrm{CH}_{4}$ increases from $2 \%$ at $650{ }^{\circ} \mathrm{C}$ to $6 \%$ at $950{ }^{\circ} \mathrm{C}$. If $\mathrm{CH}_{4}$ is regarded as a stable species that is difficult to convert to $\mathrm{H}_{2}$ by further steam reforming, these results could indicate that pyrolysis at low temperature is recommended.

The CO concentration seems to increase with temperature from $22 \%$ at $650{ }^{\circ} \mathrm{C}$ to $47 \%$ at $800{ }^{\circ} \mathrm{C}$, and is constant until $950{ }^{\circ} \mathrm{C}$.

At this point, we compare the experimental results to the composition of the gas phase at thermodynamic equilibrium. More precisely, we compare the values of $\mathrm{H}_{2} / \mathrm{CO}$ obtained experimentally with pine wood to results found using the software FactSage. At each temperature, the $\mathrm{C}-\mathrm{H}-\mathrm{O}-\mathrm{N}-\mathrm{S}$ composition of the gas phase at the exit of the reactor was introduced into FactSage as initial conditions; the equilibrium composition was then computed by minimising the Gibbs energy. The presence of tars and of solid carbon residue was neglected in this approach. Results are plotted in Fig. 9. The computed $\mathrm{H}_{2} / \mathrm{CO}$ ratio is higher than that obtained experimentally, whatever the temperature. Temperature increase is accompanied by an increase in the experimental $\mathrm{H}_{2} / \mathrm{CO}$ ratio. Experimental gas phase composition is thus very far from the thermodynamic equilibrium at the lower temperature, but tends towards it at the higher temperature, despite

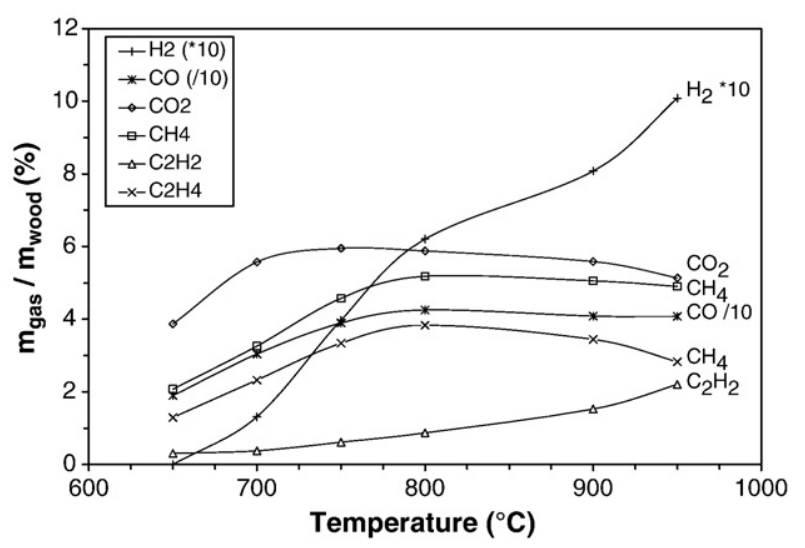

Fig. 8. Evolution of the gas species mass (normalised to the initial mass of biomass) versus temperature during pyrolysis of wood under $\mathrm{N}_{2}$ and sampled at $80 \mathrm{~cm}$ downstream of the injection point (residence time ranged from 1.4 to $1.6 \mathrm{~s}$ ).

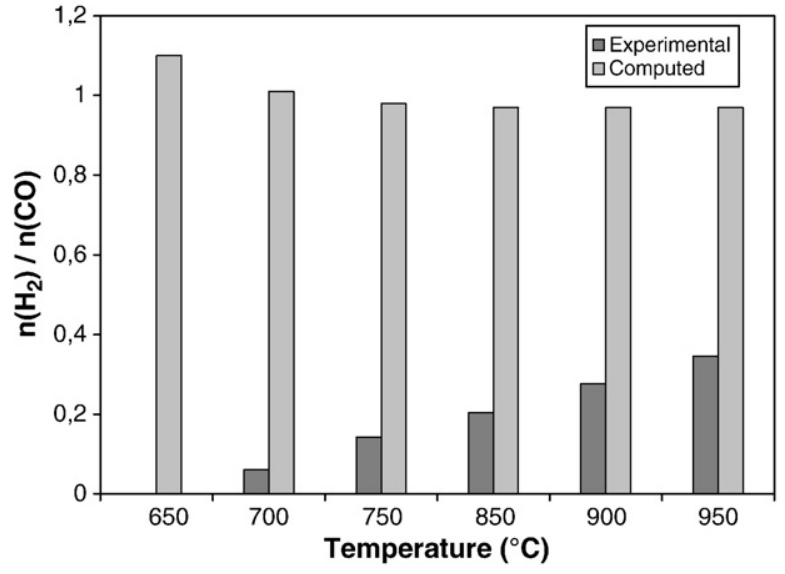

Fig. 9. Comparison of $\mathrm{H}_{2} / \mathrm{CO}$ mole ratio measured in experiments of wood pyrolysis and computed by equilibrium calculations.

not reaching equilibrium, even at $950{ }^{\circ} \mathrm{C}$. At this temperature under $1000{ }^{\circ} \mathrm{C}$, it is clear that reactions are under kinetic control.

\subsection{Influence of particle initial moisture}

As flash pyrolysis is a very rapid process, one can wonder if removing the moisture initially present in particles, a very endothermic reaction, would accelerate or slow down the process and/or impact on the amounts of the gas species formed. The $\mathrm{H}_{2} \mathrm{O}$ coming from wood natural moisture can also modify the apparent kinetics by reacting with biomass following the heterogeneous gasification reaction. Two tests were run, the first one with initial pine wood moisture of $10.7 \%$, the second one with pine wood dried at $105^{\circ} \mathrm{C}$ for $24 \mathrm{~h}$ (no moisture). These two woods (wet and dry) were pyrolysed at $850{ }^{\circ} \mathrm{C}$ for 0.9 to $1.5 \mathrm{~s}$ under nitrogen. The results obtained are presented in Fig. 10.

The results are very similar for all the gas species quantified. It can be concluded that there is no influence of natural moisture on the nature and the amounts of the gases finally resulting from pyrolysis.

\subsection{Influence of the nature of the atmosphere}

Until now, experiments have been carried out under $\mathrm{N}_{2}$. However, in a gasification process, steam-either resulting from wood drying or injected in the reactor-is present in large amounts. The presence of

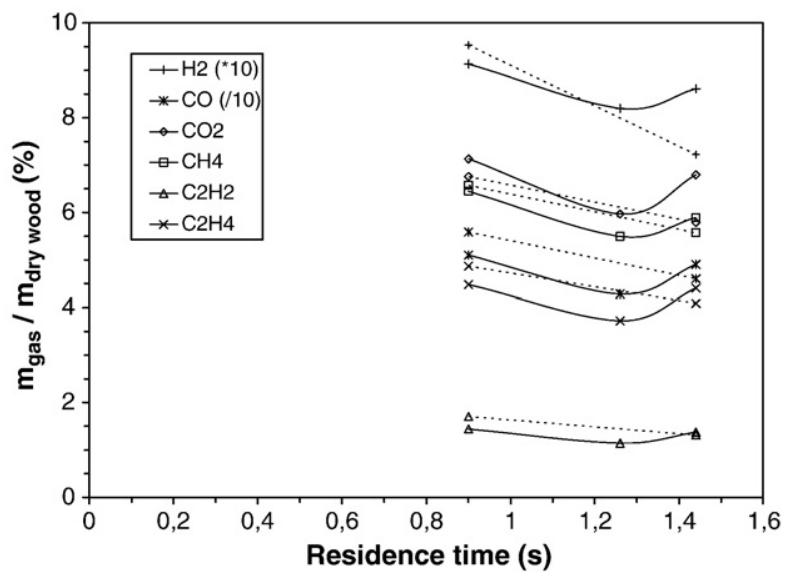

Fig. 10. Gas species mass (normalised to the initial mass of dry biomass) of dry (lines) and wet (dotted lines) wood pyrolysed at $850{ }^{\circ} \mathrm{C}$ under $\mathrm{N}_{2}$. 
steam in the gas phase can affect the process through different mechanisms:

- it can modify the heating rate of particles since the radiation is by far more efficient in the presence of steam than in nitrogen alone;

- it can favour chemical reactions such as tar cracking or water-gasshift reaction.

The effect of steam was here characterised by performing two experiments in the EFR according to conditions described in Table 2. Pine wood was thus pyrolysed at $900{ }^{\circ} \mathrm{C}$ for 0.8 to $1.5 \mathrm{~s}$ in the reactor under atmosphere containing nitrogen with alternatively 0 or $10 \mathrm{vol} . \%$ of steam. One can note that the initial moisture of wood, after drying, led to the formation of steam in the reducing atmosphere. In the present work, it was equivalent to 0.86 vol.\% steam only in the atmosphere.

In order to compare the effect of the nature of the atmosphere on pyrolysis, we have converted results to show the difference between gas yield under 10 vol.\% of steam and under nitrogen. Values are positive when gas yields under $10 \mathrm{vol}$ \% of steam are higher than gas yields under nitrogen, and vice versa. Results plotted in Fig. 11 show that the higher the initial steam concentration (10\%), the higher the $\mathrm{H}_{2}$ concentration and the lower the $\mathrm{CO}$ concentration. The occurrence of the water-gas-shift reaction might be an explanation for this result. From 0 to $10 \%$ of initial steam concentration, CO concentration decreases by $2.810^{-3} \mathrm{~mol} / \mathrm{g}_{\text {wood }}$ while hydrogen increases by $1.210^{-3} \mathrm{~mol} / \mathrm{g}_{\text {wood }}$. However, $\mathrm{CO}_{2}$ concentration increases by $4.910^{-4} \mathrm{~mol} / \mathrm{g}_{\text {wood }}$ when it should have increased of circa $1.210^{-3} \mathrm{~mol} / \mathrm{g}_{\text {wood }}$ (equal to hydrogen increase) if water-gasshift was the only reaction involved. It can be concluded that the water-gas-shift reaction alone cannot explain the changes in the gas phase composition when steam is added to the atmosphere.

No significant influence of the steam partial pressure in the atmosphere is observed on $\mathrm{CH}_{4}, \mathrm{C}_{2} \mathrm{H}_{4}$ and $\mathrm{C}_{2} \mathrm{H}_{2}$ concentrations.

As regards the possibility of an attack on the char residue by steam, this reaction is not likely to occur significantly at such a low temperature. It has indeed been shown $[29,30]$ that even at a temperature of $1000{ }^{\circ} \mathrm{C}$, it takes several tenths of minutes to gasify char.

\section{Conclusion}

The experimental work carried out made it possible to characterise quantitatively the influence of the main process parameters of flash pyrolysis of thin wood particles seen here as the first step of the conversion of wood to syngas $\left(\mathrm{H}_{2}\right.$ and $\left.\mathrm{CO}\right)$. Experiments in this field remain delicate and have to be repeated for a better accuracy. The quantification of gas species is highly repeatable, while that of char and tars needs to be improved.

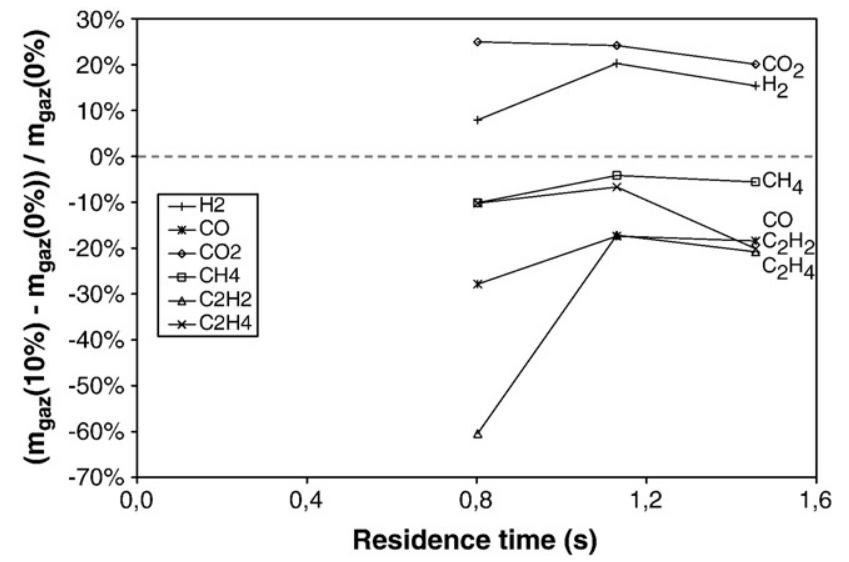

Fig. 11. Difference of gas yield formed during wood pyrolysis at $900{ }^{\circ} \mathrm{C}$ between $10 \%$ and $0 \%$ of steam concentration in nitrogen.
At $850{ }^{\circ} \mathrm{C}$, regardless of particle size between $80-125$ and 160 $200 \mu \mathrm{m}$, both the pyrolysis and tar cracking essentially happen in very short residence time period: less than $0.6 \mathrm{~s}$; the products yields are only slightly modified after $0.6 \mathrm{~s}$ in the short residence times (several seconds) of our experiments, and each gas yields remain unchanged.

The stick-shaped wood particles sometimes keep their initial shape and shrink, and sometimes change to spherical hollow spheres with a diameter close to the initial diameter of the stick.

The amount of each gas species largely depends on the temperature level in the range 650 to $950{ }^{\circ} \mathrm{C}$. Hydrogen concentration is largely improved by the temperature increase while $\mathrm{CO}$ decreases.

From the mass balance established after $2 \mathrm{~s}$ at $950{ }^{\circ} \mathrm{C}, 76 \%$ of the mass of wood is recovered as gases, $7 \%$ as char and $1.5 \%$ as tars. In our experimental conditions, the gas species taken alone (excluding char residue and tars) never reach the thermodynamic equilibrium, but tend towards it at the highest temperature.

The increase in the steam partial pressure favours the production of hydrogen, although yields remain low. Between 0 and $10 \%$ of steam, the $\mathrm{H}_{2}$ mass fraction increases from 1.3 to $1.6 \% \mathrm{w}$ and $\mathrm{CO}$ decreases from 50.0 down to $42.2 \% \mathrm{w}$. The presence of water induces a number of chemical reactions in the gas phase. The water-gas-shift reaction alone cannot explain the differences observed.

\section{Acknowledgement}

We would like to thank the Institut Français du Pétrole, which has supported this research.

\section{References}

[1] M. Guerrero, M.P. Ruiz, M.U. Alzueta, R. Bilbao, A. Millera, Pyrolysis of eucalyptus at different heating rates: studies of char characterization and oxidative reactivity, J. Anal. Appl. Pyrol. 74 (2005) 307-314.

2] R.V. Belosludov, S. Sakahara, K. Yajima, S. Takami, M. Kubo, A. Miyamoto, Combinatorial computational chemistry approach as a promising method for design of Fischer-Tropsch catalysts based on Fe and Co, Appl. Surf. Sci. 182 (3-4) (2002) 245-252.

[3] C. Dupont, J.M. Commandré, P. Gauthier, G. Boissonnet, S. Salvador, D. Schweich, Biomass pyrolysis experiments in an analytical entrained flow reactor between 1073 and $1273 \mathrm{~K}$, Fuel 87 (2008) 1155-1164.

[4] D. Vamvuka, E. Kakaras, E. Kastanaki, P. Grammelis, Pyrolysis characteristics and kinetics of biomass residuals mixtures with lignite, Fuel 82 (2003) 1949-1960.

[5] A.V. Bridgwater, G.V.C. Peacock, Fast pyrolysis processes for biomass, Renewable Sustainable Energy Rev. 4 (2000) 1-73.

[6] H.B. Goyal, Diptendu Seal, R.C. Saxena, Bio-fuels from thermochemical conversion of renewable resources: a review, Renewable Sustainable Energy Rev. 12 (2008) 504-517.

7] M.R. Gray, W.H. Corcoran, G.R. Gavalas, Pyrolysis of a wood-derived material. Effects of moisture and ash content, Ind. Eng. Chem. Process Des. Dev. 24 (1985) 646-651.

[8] S. Rapagna, N. Jand, A. Kiennemann, P.U. Foscolo, Steam-gasification of biomass in a fluidised-bed of olivine particles, Biomass Bioenergy 19 (2000) 187-197.

[9] C. Di Blasi, C. Branca, A. Santoro, R.A.P. Bermudez, Weight loss dynamics of wood chips under fast radiative heating, J. Anal. Appl. Pyrol. 57 (2001) 77-90.

[10] L. Van De Steene, S. Salvador, A. Napoli, Rice husk, straw and bark behaviour during pyrolysis, combustion, and gasification: fundamental study, 12th European Conference and Technology Exhibition on Biomass for Energy, Industry and Climate Protection, Amsterdam RAI International, The Netherlands, 17-21 June 2002.

[11] X. Shuangning, L. Zhihe, L. Baoming, Y. Weiming, B. Xueyuan, Devolatilisation characteristics of biomass at flash heating rate, Fuel 85 (2006) 664-670.

[12] B.M. Wagenaar, E.J.M.T. Van Den Heuvel, Co-combustion of miscanthus in pulverised coal combustor: experiments in a droptube furnace, Biomass Bioenergy 12 (3) (1997) 185-197.

[13] S. Li, S. Xu, S. Liu, C. Yang, Q. Lu, Fast pyrolysis of biomass in free-fall reactor for hydrogen-rich gas, Fuel Process. Technol. 85 (2004) 1201-1211.

[14] V. Visentin, F. Piva, P. Canu, Experimental study of cellulose fast pyrolysis in a flow reactor, Ind. Eng. Chem. Res. 41 (2002) 4965-4975.

[15] E. Cetin, B. Moghtaderi, R. Gupta, T.F. Wall, Influence of pyrolysis conditions on the structure and gasification reactivity of biomass chars, Fuel 83 (16) (2004) 2139-2150.

[16] D.L. Brink, M.S. Massoudi, A flow reactor technique for the study of wood pyrolysis. I. Experimental, J. Flame Flammability 9 (1978) 176-188.

[17] Commandré JM. Formation des oxides d'azote lors de la combustion de cokes de pétrole dans des conditions de précalcinateur de cimenterie. PhD thesis 2002 Institut National Polytechnique de Toulouse: Toulouse, France. 
[18] R. Zanzi, K. Sjöström, E. Björnbom, Rapid high-temperature pyrolysis of biomass in a free-fall reactor, Fuel 75 (5) (1996) 545-550.

[19] R. Zanzi, K. Sjöström, E. Björnbom, Rapid pyrolysis of agricultural residues at high temperature, Biomass Bioenergy 23 (5) (2002) 357-366.

[20] C. Di Blasi, C. Branca, Kinetics of primary products formation from wood pyrolysis, Ind. Eng. Chem. Res. 40 (2001) 5547-5556.

[21] C. Meesri, B. Moghtaderi, Lack of synergetic effects in the pyrolytic characteristics of woody biomass/coal blends under low and high heating rate regimes, Biomass Bioenergy 23 (2002) 55-66.

[22] C. Couhert J.M. Commandré, S. Salvador, Is it possible to predict gas yields of any biomass after rapid pyrolysis at high temperature from its composition in cellulose, hemicellulose and lignin? Fuel 88 (2009) 408-417.

[23] ECN Phyllis Database, http://www.ecn.nl/phyllis/dataTable.asp.

[24] L. Van De Steene, S. Salvador, G. Charnay, Controlling powdered fuel combustion at low temperature in a new entrained flow reactor: laboratory experiments and modelling, Combust. Sci. Technol. 159 (2000) 255-279.
[25] Dupont C. Vapogazéification de la biomasse: contribution à l'étude de la phénoménologie entre 800 et $1000^{\circ} \mathrm{C}$. PhD Thesis 2006. Université Claude Bernard: Lyon, France

[26] P.R. Bonelli, P.A. Della Rocca, E.G. Cerrella, A.L. Cukierman, Effect of pyrolysis temperature on composition, surface properties and thermal degradation rates of Brazil nut shells, Bioresour. Technol. 76 (2001) 15-22.

[27] J. Lédé, H.Z. Li, J. Villermaux, Fusion-like behaviour of wood pyrolysis, J. Anal. Appl. Pyrol. 10 (1987) 291-308.

28] ECN Thersites Database, http://www.thersites.n.

29] W. Klose, M. Wolki, On the intrinsic reaction rate of biomass char gasification with carbon dioxide and steam, Fuel 84 (2005) 885-892.

[30] F. Mermoud, F. Golfier, S. Salvador, L. Van De Steene, J.L. Dirion, Experimental and numerical study of steam gasification of a single charcoal particle, Combust. Flame 145 (2006) 59-79. 